NOTA DE PESQUISA

\title{
MÉTODO ESTIMATIVO PARA AMOSTRAGEM QUANTITATIVA DE Rondonia rondoni (NEMATODA: ATRACTIDAE) PARASITO DE PEIXES*
}

\author{
CRISTIANE M. DE CAMPOS ${ }^{1,2}$; FLÁVIO R. DE MORAES²; GENER T. PEREIRA ${ }^{3}$
}

\begin{abstract}
CAMPOS, C.M. DE; MORAES, F.R. DE; PEREIRA, G.T. [Estimative method for quantitative sampling of Rondonia rondoni (Nematoda: Atractidae) parasite of fish.] Método estimativo para amostragem quantitativa de Rondonia rondoni (Nematoda: Atractidae) parasito de peixes. Revista Brasileira de Parasitologia Veterinária, v. 16, n. 3, p. 174-176, 2007. Universidade Estadual de Mato Grosso do Sul, Unidade Universitária de Aquidauana, Rod. Aquidauana-CERA, km 12, Zona Rural, Aquidauana, MS 79200-000. E-mail: cmeldau@uems.br

The presente work evaluated the number of Rondonia rondoni in intestine of Piaractus mesopotamicus, for diference of dry and wet weight of parasites samples by each host, from the relation dry weight and number of parasites. Totals samples of $R$. rondoni of 37 specimens of $P$. mesopotamicus for attaiment of wet weight, dehydrated in stove with temperature between $55^{\circ} \mathrm{C}$ and $60^{\circ} \mathrm{C}$, the wet weight was measured after $24 \mathrm{~h}$. The number of parasites was calculated with rule of three, considering the average number of $1,010 \pm 6.027$ specimens quantified in previous assay. The equation of linear regression is $y=13.138 x-162.01$ and $r^{2}=0.9989$. The normality of the data was proven with Kolmogorov-Smirnov ( $\mathrm{p}<0.01$ ).
\end{abstract}

KEY WORDS: Estimate, weight, nematoda, fish.

\section{RESUMO}

O objetivo deste trabalho foi avaliar o número de Rondonia rondoni no intestino de Piaractus mesopotamicus, por meio da diferença entre peso úmido e peso seco das amostras de parasitos para cada hospedeiro, a partir da relação do peso seco e número de parasitos pré-estabelecida. Amostras totais de $R$. rondoni, de 37 espécimes de Piaractus mesopotamicus, foram medidas para obtenção do peso úmido, desidratadas em estufa com temperatura entre $55^{\circ} \mathrm{C}$ e $60^{\circ} \mathrm{C}$ e, após $24 \mathrm{~h} \mathrm{seu}$ peso seco foi determinado. Por meio de uma regra de três simples, calculou-se o número de parasitos a partir da diferença entre o peso úmido e o peso seco, considerando um erro padrão médio de 6,027 para um número médio de 1010 indi-

*Este trabalho é parte da tese de doutorado do primeiro autor; Financiado pela CAPES.

${ }^{1}$ Universidade Estadual de Mato Grosso do Sul, Unidade Universitária de Aquidauana, Rod. Aquidauana-CERA, km 12, Zona Rural, Aquidauana, MS 79200-000. E-mail: cmeldau@uems.br

${ }^{2}$ Centro de Aqüicultura da Universidade Estadual Júlio de Mesquita Filho (Unesp), Campus de Jaboticabal, Via de acesso Prof. Paulo Donato Castellane s/n, Jaboticabal, SP 14884-900.

${ }^{3}$ Unesp, Campus de Jaboticabal, SP. víduos, quantificado em ensaio prévio. A equação da regressão linear estimada foi de $y=13,138 x-162,01$ e r $^{2}=0,9989$, a qual foi significativa ( $\mathrm{p}<0,01)$, sendo $y$ o número de parasitos e $x$ o peso seco. A normalidade dos dados foi verificada com o teste de Kolmogorov-Smirnov significativo para $\mathrm{p}<$ 0,01 .

PALAVRAS-CHAVE: Estimativa, peso, nematoda, peixe.

A quantificação de parasitos por meio de métodos estimativos é comum em trabalhos científicos, principalmente, quando se trata de contagem de parasitos de peixes de ambientes naturais, tais como rios e reservatórios. Nesses locais, a possibilidade dos parasitos encontrarem todos os seus hospedeiros, intermediários, paratênicos e/ou definitivos é, geralmente, maior do que em ambientes de criação. Isso é verdadeiro para a maioria dos helmintos que precisa de um ou mais hospedeiros para completar seu ciclo vital.

Métodos estimativos de contagem também são utilizados para grupos distintos de parasitos, desde protozoários a metazoários. A quantificação de protozoários como Ichthyophthirius multifilis e Piscinoodinium pillulare, em 
peixes, foi feita por contagem em câmara de Macmaster por Tavares-Dias et al. (2001). Barse (1998) estudando parasitos de brânquias de Fundulus heteroclitus (Teleostei: Cyprinodontidae) analisou somente arcos branquiais do lado direito do hospedeiro, na tentativa de diminuir o tempo gasto na contagem de monogêneas e copépodes e, minimizar o efeito da perda dos parasitos que ocorre após a morte do hospedeiro. O autor fez 18 sub-amostragens por brânquias, representando um total de 17 \% do total de infecção para as brânquias do lado direito. Posteriormente, a contagem foi dividida por 0,17 para estimar o total de infecção para essas brânquias e multiplicado por dois para obter a densidade de cada espécie de parasito.

Considerando os endohelmintos intestinais Catto e Amato (1994) estudaram a estrutura da comunidade parasitária em Caiman crocodilus yacare (Crocodylia: Alligatoridae) no Pantanal brasileiro e quantificaram as espécies de helmintos encontradas no intestino do hospedeiro. No caso de suspeita de presença de mais de 200 parasitos no intestino, os autores examinavam duas amostras de $10 \%$.

Dias et al. (2004) estudando a carga parasitária de Rondonia rondoni em Pterodoras granulosus (Osteichthyes: Doradidae) trabalharam com sub-amostragem. Os intestinos com grande quantidade de nematodas foram fixados inteiros. Todo o conteúdo intestinal passou por um jogo de peneiras de malhas diferentes, para lavagem e sub-amostras de $25 \%$ do conteúdo foram retiradas. A amostra era colocada em um fracionador com duas seç̧ões, homogeneizada e dividida inicialmente em duas partes e, posteriormente, em mais duas, obtendo-se assim $1 / 4$ da amostra. A contagem foi realizada com esse $1 / 4$, a partir do qual se obteve o total estimado de parasitos por meio de regra de três.

O nematoda $R$. rondoni é comumente encontrado em quantidades excessivas na luz do intestino de peixes de ambientes naturais, como o pacu Piaractus mesopotamicus. Essa espécie de parasito é vivípara e adultos e larvas podem ser vistos em grande intensidade de parasitismo no intestino, entretanto, os peixes são quase sempre assintomáticos (PAVANELLI et al., 2002).

Em coletas realizadas nos rios Aquidauana e Miranda, no Pantanal Sul, no período de 2003 a 2004, 73,97 \% da amostra de Piaractus mesopotamicus (Osteichthyes: Characidae) estava parasitada por $R$. rondoni com intensidade média de 10.032,7 parasitos (CAMPOS, 2006). Com o intuito de reduzir o tempo dedicado a quantificação de parasitos e minimizar as perdas que efetivamente ocorrem após a morte do hospedeiro neste trabalho é proposto um novo método estimativo para quantificação de $R$. rondoni em peixes.

O objetivo deste trabalho foi avaliar o número de $R$. rondoni no intestino de pacus Piaractus mesopotamicus, por meio da diferença entre peso úmido e peso seco das amostras de parasitos para cada hospedeiro, a partir da relação do peso seco e número de parasitos pré-estabelecida.

Inicialmente, três espécimes de pacus tiveram seu intestino dissecado, foi feita a triagem dos parasitos e uma sub-amos- tra de $R$. rondoni foi retirada do conteúdo intestinal de cada peixe para estabelecer uma relação entre peso seco e número de parasitos. Essas três sub-amostras de $R$. rondoni foram previamente quantificadas e o número médio encontrado foi de $1010 \pm$ 6,027 (média \pm erro médio) indivíduos, entre larvas e adultos. Posteriormente, as sub-amostras, armazenadas em recipientes feitos de papel alumínio, foram desidratadas em estufa entre $55^{\circ} \mathrm{C}$ a $60^{\circ} \mathrm{C}$, durante $24 \mathrm{~h}$ para obtenção do peso seco. As sub-amostras foram pesadas em balança digital e o peso seco médio obtido foi de $77,24 \mathrm{mg}$, com desvio padrão de $0,0005 \mathrm{mg}$. Com isso estabeleceu-se a relação entre peso seco e número total de parasitos, considerando que uma amostra com peso de 77,24 mg continha em média 1010 parasitos.

A partir desses dados, foram estudados 37 espécimes de pacus coletados nos rios Aquidauana e Miranda, no período compreendido entre março de 2003 a fevereiro de 2004. As amostras totais de cada hospedeiro, após triagem de todos os outros helmintos, com exceção de $R$. rondoni, foram medidas para obtenção do peso úmido, desidratadas em estufa na margem de temperaturas supracitadas e, após $24 \mathrm{~h}$ seu peso seco foi obtido.

Por meio de uma regra de três simples, calculou-se o número de parasitos a partir da diferença entre o peso úmido e o peso seco, considerando um erro padrão médio de 6,027 para um número médio de 1010 indivíduos, quantificado em ensaio prévio. A equação da regressão linear estimada foi $\mathrm{y}=$ $13,138 \mathrm{x}-162,01 \mathrm{e} \mathrm{r}^{2}=0,9989$, a qual foi significativa $(\mathrm{p}<$ 0,01 ), sendo $y$ o número de parasitos e $x$ o peso seco (Figura $1)$.

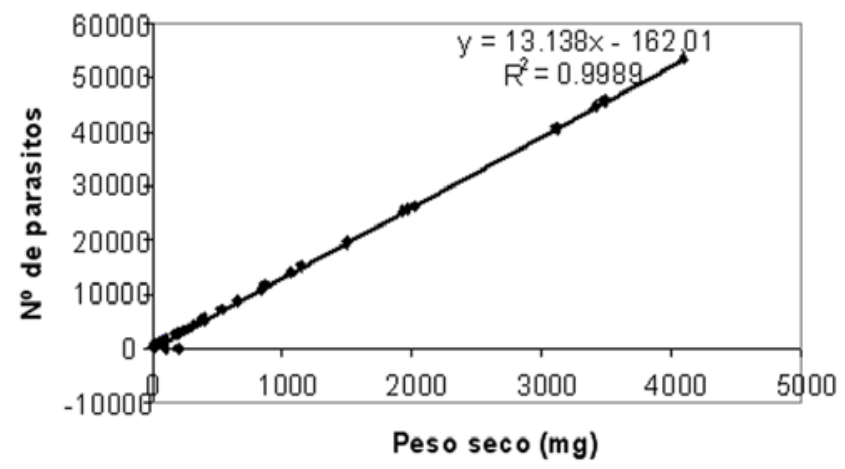

Figura 1. Quantidade estimada de Rondonia rondoni em 37 espécimes de Piaractus mesopotamicus capturados nos rios Aquidauana e Miranda, MS.

Este método mostrou-se eficiente para estimar o número de parasitos que ocorrem em grandes quantidades, não apresentando diferença significativa quando comparada as amostras que tiveram todos os indivíduos, entre larvas e adultos, quantificados. Porém, é válido ressaltar que o método prevê a desidratação dos parasitos inviabilizando, posteriormente, a montagem de lâminas.

\section{REFERÊNCIAS BIBLIOGRÁFICAS}

BARSE, A.M. Gill parasites of mummichogs, Fundulus 
heteroclitus (Teleostei: Cyprinodontidae): effects of season, locality, and host sex and size. Journal of Parasitology, v.84, n.2, p.236-244, 1998.

CAMPOS, C.F.M. Fauna parasitária e alterações teciduais de peixes dos rios Aquidauana e Miranda, Pantanal Sul Mato-Grossense. 2006. 116 f. Tese (Doutorado em Aqüicultura) - Centro de Aqüicultura. Universidade Estadual Paulista “Júlio de Mesquita Filho”, Jaboticabal, 2006.

CATTO, J.B.; AMATO, J.F.R. Helminth community structure of the Caiman crocodilus yacare (Crocodylia, Alligatoridae) in the brazilian "Pantanal". Revista Brasileira de Parasitologia Veterinária, v.3, n.2, p.109-118, 1994.
DIAS, P. G.; FURUYA, W.M.; PAVANELLI, G.C.; MACHADO, M.H.; TAKEMOTO, R.M. Carga parasitária de Rondonia rondoni Travassos, 1920 (Nematoda, Atractidae) e fator de condição do armado, Pterodoras granulosus Valenciennes, 1833, (Pisces, Doradidae). Acta scientiarum: Biological Sciences, v.26, n.2, p.151-156, 2004.

PAVANELLI, G.C.; EIRAS, J.C.; TAKEMOTO, R.M. Doenças de Peixes: profilaxia, diagnóstico e tratamento. Maringá: EDUEM: NUPÉLIA, 2. ed. 2002, 305p.

TAVARES-DIAS, M.; MARTINS, M.L.; MORAES, F.R. Fauna parasitária de peixes oriundos de "pesque-pague" do município de Franca, São Paulo, Brasil. I. Protozoários. Revista Brasileira de Zoologia, v.18, supl.1, p.67-79, 2001.

Recebido em 12 de fevereiro de 2007.

Aceito para publicação em 30 de agosto de 2007. 